\title{
Risk Factors of Dementia in Elderly of Bandung City, Indonesia: A Community-Dwelling Study
}

\author{
Sarah Fitri Janaris, ${ }^{1}$ Sharon Gondodiputro, ${ }^{2}$ Nita Arisanti ${ }^{2}$ \\ ${ }^{1}$ Faculty of Medicine Universitas Padjadjaran, Indonesia, ${ }^{2}$ Department of Public Health \\ Faculty of Medicine Universitas Padjadjaran, Indonesia
}

\section{Abstract}

Background: Multiple organ degenerative processes are parts ofa normal biological process in aging. One of the geriatric syndromes is cognitive disorders that range from a mild cognitive impairment to dementia. The aim of this study was to analyze factors contributing to the occurrence of dementia in the elderly.

Methods: A cross-sectional analytical study was conducted using secondary data on 306 elderly people who visited the Integrated Health Post (Pos Pembinaan Terpadu, Posbindu) from June to August 2016 in Bandung City, Indonesia. Nine variables were included in this study:age, gender, education level, marital status, occupation, living arrangements, social participation, comorbidity, and dementia. The dementia status was measured by the Mini-Mental State Examinationand Mini Cog Assessment instruments. Data were then analyzed statistically using Chi-Square, Fisher Exact, and Kolmogorov-Smirnov tests, as well as using the multivariate logistic regression.

Result: Around 35.3\% (95\% CI=30\%-40.6\%) of respondents had dementia. There were relationships between dementia and age $(\mathrm{p}=0.035)$, level of education $(\mathrm{p}=0.000)$, and social participation $(\mathrm{p}=0.001)$. Social participation was the most dominant risk factor of dementia (OR=2.703;95\%CI=1.491-4.902). Conclusions: Age, education level, and social participation are risk factors that contribute to dementia. The elderly who has less than two times per week of social participation has a 2.7 times higher risk for having dementia compared to the elderly who has more than two times per week of social participation.

Keywords: Dementia, elderly, Mini-Mental State Examination, risk factors

\section{Introduction}

Indonesia faces a progressive increase in the elderly population. Cognitive disorders as one of the geriatric syndromes have the risk to develop into mild cognitive impairment and dementia. ${ }^{1-3}$ According to the World Health Organization (WHO), there are 50 million people in the world experiencing dementia and 10 million new cases annually. ${ }^{3}$ It is estimated that the number of people in the Asia-Pacific region experiencing dementia will increase by the amount of 23 million in 2015 to 71 million people in 2050, including in Indonesia that are expected to experience dementia with around 4 million people in $2050 .{ }^{4}$

There are various risk factors for dementia, including age, gender, marital status, education level, occupation, genetic carrier APOE allele 4, drug consumption, comorbidity, living arrangements, and outdoor activities., ${ }^{2,5-7}$

The purpose of this study was to analyze risk factors related to the occurrence of dementia in the elderly in the community. This study is expected to be useful information for primary health care in finding the risk factors associated with dementia for early detection and preventing the development of dementia.

\section{Methods}

An analytical cross-sectional study was carried out using the secondary datacollected from June to August 2016, consisted of the characteristics of the respondents, the Mini-Mental State Examination (MMSE) instrument, and the Mini-Cog Assessment instrument (Mini-Cog). The respondents were elderly who visited the Integrated Health Post (Pos Pembinaan Terpadu, Posbindu). The

Correspondence: Sarah Fitri Janaris, Faculty of Medicine Universitas Padjadjaran, Jalan Raya Bandung-Sumedang Km. 21, Jatinangor, Sumedang, Indonesia, Email: sarahfitri915@gmail.com. 
total number of Posbindu was 29 Posbindu. The selection of respondents was conducted based on consecutive sampling, while Posbindu selection was performed based on a simple random sampling. This study had been approved by the Ethics Committee of Universitas Padjadjaran Bandung, Indonesia, No. 759/UN6.KEP/EC/2019.

The inclusion criteria were male and female, aged $\geq 60$ years. The dementia was measured based on the measurement of MMSE. The exclusion criteria were answers to questionnaires that could not be read by the researchers. Based on these criteria, 306 of the 313 questionnaires were included in this study. The variables included in this study were 9 variables consisted of 1) age, were grouped into $60-70$ years old and $>70$ years old; 2 ) gender was classified into "male" and "female"; 3) the level of education was grouped into "has no formal education" or the last education was"elementary school "junior high school", "senior high school", or "higher than senior high school"; 4) the marital status was classified into "no spouse" and "has a spouse"; 5) occupation was grouped into "not working" and "working"; 6) household arrangements were grouped into "live alone", "with spouses only", "with spouses and or other family members"; 7) social participation within one week weregrouped into "0-1 times/week" and " $\geq 2$ times/week"; 8) diseases/symptoms wereclassified into "no diseases or symptoms", "one disease or symptoms", "two diseases or symptoms", and "more than two diseases or symptoms"; and 9) dementiawasgrouped into "dementia" and "not dementia". Dementiawas designated when the respondent had a score of MMSE $\leq 23$ for respondents with the highest level of education was high school or $\leq 25$ for respondents with an education level higher than high school. For the respondent who could not read and write, a Mini-Cog instrument was used with a cut-off point $<3$ designated as dementia.

The collected data were analyzed using IBM SPSS Statistics Software, Version 22.0. The bivariate analysis using Chi-Square statistical test was conducted on age, gender, education level, marital status, occupation, social participation, and disease status. The statistical test of Kolmogorov-Smirnov was performed on the living arrangements variable. Moreover, a multivariate logistical

Table 1 Characteristics of Elderly Visited the Integrated Health Post (Posbindu)

\begin{tabular}{|c|c|c|}
\hline Characteristics & Frequency (n) & Percentage (\%) \\
\hline \multicolumn{3}{|l|}{ Age (years old) } \\
\hline $60-70$ & 204 & 66.7 \\
\hline$>70$ & 102 & 36.3 \\
\hline \multicolumn{3}{|l|}{ Gender: } \\
\hline Female & 245 & 80.1 \\
\hline Male & 61 & 19.9 \\
\hline \multicolumn{3}{|l|}{ Education level: } \\
\hline$\leq$ Elementary School & 169 & 55.2 \\
\hline Junior High School & 54 & 17.7 \\
\hline Senior High School & 60 & 19.6 \\
\hline$>$ Senior High School & 23 & 7.5 \\
\hline \multicolumn{3}{|l|}{ Marital Status: } \\
\hline No spouse & 149 & 48.7 \\
\hline With Spouse & 157 & 51.3 \\
\hline \multicolumn{3}{|l|}{ Occupation: } \\
\hline Not working & 243 & 79.4 \\
\hline Still working & 63 & 20.6 \\
\hline
\end{tabular}


Table 2 Domains of the Cognitive Impairment using MMSE Instruments*

\begin{tabular}{lcc}
\hline \multicolumn{1}{c}{ Domains } & Normal (\%) & Impaired (\%) \\
\hline Orientation & $223(78.0)$ & $63(22.0)$ \\
Memory & $176(61.5)$ & $110(38.5)$ \\
Attention and Calculation & $188(65.7)$ & $98(34.4)$ \\
Language & $222(77.6)$ & $64(22.4)$ \\
Constructional Praxis & $97(31.7)$ & $189(66.1)$ \\
\hline
\end{tabular}

Notes: *from 306 questionnaires, only 286 questionnaires included, consisted of the MMSE test result

regression test was performed on variables that had a p-value $<0.25$ of the bivariate statistical test results. In the selected variables, a multicollinearity test was also performed to identify a strong correlation between two or more independent variables. The results of the test were strongly correlated when the value of Variance Inflation Factor (VIF) $>5$, correlates moderately when the VIF value was $<1$ or $\leq 5$, and there was no correlation if the value of VIF $=1.8$ Furthermore, the pseudo-R2 test with Cox \& Snell and Nagelkerke also performed to determine the predictable variable variance of the dependent variables from the independent variables.

\section{Results}

From 306 questionnaires, there were 286 questionnaires obtained using the MMSE and 20 questionnaires obtained using the Mini-Cog instrument. Table 1 showed that most of the respondents were $60-70$ years old $(66.7 \%)$, predominantly female $(80.1 \%)$, and most of them had an education level of junior high school (72.88\%), still living with their spouse (51.3\%), and had no work (79.4\%).

The study found that the proportion of dementia measured by MMSE was quite high at $35.3 \% \quad(95 \% \mathrm{CI}=30 \%-40.6 \%)$. The MMSE questionnaire measured 5 domains of cognitive impairment, i.e. orientation; memory and calculations; language and, constructional praxis (the ability to draw objects). The results showed that the most cognitive disorder discovered in this study was impaired in the constructional praxis $(66.1 \%)$, as shown in Table 2. This study showed that of the 8 risk factors, only 3 factors related to the occurrence of dementia, i.e. age, level of education, and social participation (Table 3).

A logistic regression analysis was carried out on 5 variables that had a p-value $<0.25$. Those variables were age, education level, marital status, social participation, and the status of disease/symptom. The results of the statistical test, the most dominant risk factor for the occurrence of dementia was social participation (Table 4).

The Odds Ratio of the elderly who had social participation with a frequency less than 2 times a week was 2.703 times of the Odds Ratio of the elderly who had social participation with a frequency of $\geq 2$ times a week. In the multicollinearity test, the value of the variance inflation factor (VIF) was between 1.013 and 1.215. This result indicated there was a moderate correlation between independent variables. Moreover, this study found that the value of the pseudo-R2 was 0.136 based on the tests of Cox \& Snell and 0.187 on the Nagelkerke tests. These results indicated that the proportion of variable variance can be predicted from independent variables was only $13.6 \%$ and $18.7 \%$. Social participation that was carried out by the respondents in the past week were religious activities, sports, working or trading, and arisan. The arisan was an informal social gathering that took place at a fixed interval at each member's home in turn. This social gathering was a form of rotating saving (microfinance) in Indonesian culture where a kind of lottery was conducted and members took turns to win an amount of money previously deposited by all members. (Table 5).

\section{Discussion}

Dementia in the elderly is one of the symptoms of geriatric syndrome. In this study, the proportion of dementia in the elderly is high, amounted to $35.3 \% \quad(95 \% \mathrm{CI}=30 \%-40.6 \%)$. Age, education level, and social participation are the risk factors for dementia. The elderly who have a low-frequency of social participation have a 2.7 times higher risk for dementia compared to the elderly who have a high-frequency of social participation.

The proportion of dementia in this study 
Table 3 Risk Factors Related to Dementia

\begin{tabular}{|c|c|c|c|c|}
\hline Risk Factors & Dementia (\%) & No Dementia (\%) & Total & p-value \\
\hline Age & & & & 0.011 \\
\hline $60-70$ years old & $62(30.4)$ & $142(69.6)$ & 204 & \\
\hline$>70$ years old & $46(45.1)$ & $56(54.9)$ & 102 & \\
\hline Gender: & & & & 0.660 \\
\hline Female & $85(34.7)$ & $160(65.3)$ & 245 & \\
\hline Male & $23(37.7)$ & $38(62.3)$ & 61 & \\
\hline Education level: & & & & 0.000 \\
\hline$\leq$ Elementary School & $81(47.9)$ & $88(52.1)$ & 169 & \\
\hline Junior High School & $13(24.1)$ & $41(75.9)$ & 54 & \\
\hline Senior High School & 11(18.3) & $49(81.7)$ & 60 & \\
\hline$>$ Senior High School & $3(13.0)$ & $20(87.0)$ & 23 & \\
\hline Marital Status: & & & & 0.115 \\
\hline No spouse & $46(30.9)$ & $103(69.1)$ & 149 & \\
\hline With Spouse & $62(39.5)$ & $95(60.5)$ & 157 & \\
\hline Occupation: & & & & 0.715 \\
\hline Not working & $87(35.8)$ & $156(64.2)$ & 243 & \\
\hline Still working & $21(33.3)$ & $42(66.7)$ & 63 & \\
\hline Living Arrangements & & & & $0.472^{* *}$ \\
\hline Live alone & $6(50.0)$ & $6(50.0)$ & 12 & \\
\hline With spouse only & $18(38.3)$ & $29(61.7)$ & 47 & \\
\hline With spouse and other family members & $84(34.0)$ & $163(66.0)$ & 247 & \\
\hline Social participation: & & & & 0.000 \\
\hline $0-1$ time/week & $88(45.8)$ & $104(54.2)$ & 192 & \\
\hline$\geq 2$ times/week & $20(17.5)$ & $94(73.8)$ & 114 & \\
\hline Disease/symptom: & & & & 0.141 \\
\hline No disease/symptom & $8(20.5)$ & $31(79.5)$ & 39 & \\
\hline One disease/symptom & $74(39.2)$ & $115(60.8)$ & 189 & \\
\hline Two diseases/symptoms & $22(34.9)$ & $41(65.1)$ & 63 & \\
\hline$>$ Two diseases/symptom & $4(26.7)$ & $11(73.7)$ & 15 & \\
\hline TOTAL & $108(35.3)$ & $198(64.7)$ & 306 & \\
\hline
\end{tabular}

Notes: * Fisher's Exact statistical test; ** Kolmogorov-Smirnov statistical test

is quite high compared to other studies (1.3$14.3 \%$ ) that has used the fourth edition of the Diagnostic and Statistical Manual of Mental Disorder ${ }^{2}$ and the tenth edition of the International Classification Diseases to the undetectable respondents of dementia. ${ }^{9}$ Our study has used the MMSE instrument as a screening tool for dementia. The MMSE instrument has a sensitivity of $90 \%$ and a specificity of $69 \% .^{5}$

Most of the respondents suffered a disruption in the constructional praxis domain, a visual capability that works on threedimensional spaces such as remembering a place. ${ }^{10}$ This domain can be used as early detection and diagnostic clarification tool for Alzheimer's disease and Lewy Body dementia (LBD). LBD patients with low MMSE scores 
Table 4 Multivariate Regression Logistic

\begin{tabular}{|c|c|c|c|c|c|c|c|c|c|}
\hline & \multirow[t]{2}{*}{ Variables } & \multirow[t]{2}{*}{$\boldsymbol{\beta}$} & \multirow[t]{2}{*}{ S.E. } & \multirow[t]{2}{*}{ Wald } & \multirow[t]{2}{*}{ df } & \multirow[t]{2}{*}{ Sig. } & \multirow[t]{2}{*}{$\operatorname{Exp}(\beta)$} & \multicolumn{2}{|c|}{$\begin{array}{c}\text { 95.0\% CI for } \\
\operatorname{EXP(\beta )}\end{array}$} \\
\hline & & & & & & & & Lower & Upper \\
\hline Step & Age & -0.590 & 0.278 & 4.492 & 1 & 0.034 & 0.554 & 0.321 & 0.957 \\
\hline \multirow[t]{5}{*}{$1 \mathrm{a}$} & Education level & 0.561 & 0.161 & 12.150 & 1 & 0.000 & 1.753 & 1.278 & 2.403 \\
\hline & Marital status & 0.098 & 0.275 & 0.127 & 1 & 0.722 & 1.103 & 0.644 & 1.888 \\
\hline & $\begin{array}{l}\text { Social } \\
\text { Participation }\end{array}$ & 1.003 & 0.304 & 10.862 & 1 & 0.001 & 2.727 & 1.502 & 4.952 \\
\hline & $\begin{array}{l}\text { Disease/ } \\
\text { Symptom }\end{array}$ & -0.063 & 0.185 & 0.114 & 1 & 0.735 & 0.939 & 0.653 & 1.351 \\
\hline & Constant & -0.866 & 0.774 & 1.253 & 1 & 0.263 & 0.421 & & \\
\hline Step & Age & -0.591 & 0.278 & 4.504 & 1 & 0.034 & 0.554 & 0.321 & 0.956 \\
\hline \multirow[t]{4}{*}{$2 \mathrm{a}$} & Education level & 0.563 & 0.161 & 12.264 & 1 & 0.000 & 1.757 & 1.282 & 2.408 \\
\hline & Marital status & 0.090 & 0.274 & .109 & 1 & 0.741 & 1.095 & .640 & 1.871 \\
\hline & $\begin{array}{l}\text { Social } \\
\text { Participation }\end{array}$ & 0.999 & 0.304 & 10.798 & 1 & 0.001 & 2.715 & 1.496 & 4.925 \\
\hline & Constant & -0.989 & 0.684 & 2.091 & 1 & 0.148 & 0.372 & & \\
\hline Step & Age & -0.567 & 0.268 & 4.460 & 1 & 0.035 & 0.567 & 0.335 & 0.960 \\
\hline \multirow[t]{3}{*}{$3 a$} & Education level & 0.554 & 0.158 & 12.281 & 1 & 0.000 & 1.740 & 1.276 & 2.371 \\
\hline & $\begin{array}{l}\text { Social } \\
\text { Participation }\end{array}$ & 0.995 & 0.304 & 10.727 & 1 & 0.001 & 2.703 & 1.491 & 4.902 \\
\hline & Constant & -0.862 & 0.564 & 2.336 & 1 & 0.126 & 0.423 & & \\
\hline
\end{tabular}

would have poorer manifestations in image copying tests compared to Alzheimer's patients with low MMSE scores but are succeeded in the image copying tests. ${ }^{10}$ This study has found 5 variables that are not related to dementia i.e. gender, marital status, occupation, living arrangements, and disease status. Interestingly, women have a higher risk of dementia compared to men due to genetic factors and higher female life expectancy. ${ }^{11,12}$ However, this study has shown that gender is not related to the risk of dementia. This result is likely caused by the number of female respondents, which is eight times more than male respondents. Marital status becomes one of the risk factors for dementia. An individual who has a partner tends to be able to maintain cognitive function through social support given by the partner, in opposed to a widowed man or woman, who are more prone to stress, resulting in decreased cognitive function. ${ }^{9}$ However, our study shows that marital status is not related to the risk of dementia. The difference in results obtained between this study and previous study is assumed that most of the respondents in our study have no spouse but still live with their children and other family members, therefore, social and emotional support are still provided by their family members. The working elderly have better cognitive performance than the elderly who are retired or have never worked at all. ${ }^{7}$ Work can sustain and improve cognitive function, although the aging process is taking place, the cognitive part of the brain has a better compensation for cognitive decline. ${ }^{13}$ Interestingly, our study found that the work status of the respondent was unrelated to the risk of dementia. The results are likely to occur because respondents who do not work still do other activities that could reduce the risk of dementia. The living arrangements are not related to the risk of dementia. There is no difference in the risk of mild cognitive impairment among individuals living alone with individuals living together with their partners. ${ }^{14}$ Moreover, the severity of comorbidities cannot assess the cognitive changes in dementia patients so that comorbidities are not included in the risk factors of dementia. ${ }^{15}$

There are 3 factors related to the occurrence of dementia, which are age, education level, 
and social participation. Age becomes one of the risk factors associated with the occurrence of dementia. As we age, the occurrence of mild cognitive disorders increases and this makes the chance of dementia higher. ${ }^{2}$ As for the education factor, there is an increased risk of dementia in respondents with low education. Individuals with low education levels have a lower cognitive function that makes a higher risk of dementia. ${ }^{13}$ Social and economic status had an impact on the quality of the education gained by individuals, suggesting that these factors increase the incidence of dementia. ${ }^{13}$ Furthermore, the study has found that the elderly who has a low frequency of social participation has a risk of 2.7 times higher for dementia compared to the elderly who has a high frequency of social participation. Social participation can encourage the elderly to remain active so that cognitive function can be maintained and the risk of dementia can be reduced. ${ }^{16}$ Various social participation has been conducted by the elderly. Religious activities such as religious studies (pengajian) become the main activity carried out by the elderly. Religious activities can reduce the risk of mild cognitive disorder. ${ }^{17}$ Respondents who performed religious activities on weekly basis tend to experience a slower rate of cognitive decline than those who rarely do religious activities. On the contrary, another study shows no link between religious activities and cognitive decline. It may be due to the different religious levels that may have different impacts on the cognitive function, so further study is required. ${ }^{7}$ Other social participation undertaken by respondents are sports, working, social gathering, and organizational meetings. The exercise that is carried out with a group of the elderly proved some benefits, not only physical fitness but also emotional support that can lower the risk of cognitive impairment in the elderly. ${ }^{7}$ The elderly who are actively involved with social activities can also maintain cognitive abilities and improve cognitive reserve. ${ }^{16}$ The model developed in this study has shown that the status of education and social participation are the predictors of dementia. The most dominant factor associated with dementia is the social participation factors, nevertheless, this model generated only 13.6-18.7\%, indicating that there are $81.3-86.4 \%$ other factors related to the occurrence of dementia in the elderly. This is strengthened by the result of a multicollinearity test that showed the VIF values between 1.013-1.215.

This study has some limitations. Detection of dementia in this study is only carried out by using MMSE instruments. Further examination to make a definite diagnosis of dementia is required. The method used in this study is a cross-sectional analysis, so it cannot be identified whether the respondent lives with his/her family, does not work, or does not do any activities due to dementia, or those factors that causing dementia. Another limitation of this study is that there are more female compared to male respondents. This unequal distribution has made the gender factor is not related to the occurrence of dementia. Furthermore, the pseudo-R2 produced only $13.6 \%$ and $18.7 \%$, thus, there are still other factors related to the occurrence of dementia in the elderly. These limitations, it does not reduce the importance of this study.

To conclude, this study has shown that the prevalence of dementia is quite high in the community. This situation needs to be followed up by further examination and intervention, otherwise, the occurrence of dementia will cause major problems both cognitive, physical, and social.

\section{References}

1. Senn N, Monod S. Development of a comprehensive approach for the early diagnosis of geriatric syndromes in general practice. Front Med (Lausanne). 2015;2:78.

2. Lipnicki DM, Crawford J, Kochan NA, Trollor JN, Draper B, Reppermund S, et al. Risk factors for mild cognitive impairment, dementia, and mortality: The Sydney memory and ageing study. J Am Med Dir Assoc. 2017;18(5):388-95.

3. World Health Organization. Dementia. 2017 [Cited 2019 January 24] Available from: https://www.who.int/news-room/ fact-sheets/detail/dementia

4. Alzheimer's Disease International, Alzheimer's Australia. Dementia in the Asia Pacific Region. London: Alzheimer's Disease International; 2014.

5. Katsaouni P, Papamichail E, Maillis A. Exploring dementia in primary health care: Comorbidities and diagnostic tools. Int J Caring Sci. 2017;10(1):110-6.

6. Sommerlad A, Ruegger J, Singh-Manoux A, Lewis G, Livingston G. Marriage and risk of dementia: Systematic review and metaanalysis of observational studies. J Neurol Neurosurg Psychiatry. 2018;89(3):231-8.

7. Adam S, Bonsang E, Grotz C, Perelman S. Occupational activity and cognitive reserve: 
Implications in terms of prevention of cognitive aging and Alzheimer's disease. Clin Interv Aging. 2013;8:377-90

8. Daoud JI. Multicollinearity and regression analysis. J Phys Conf Ser. 2017;949:012009.

9. Sundström A, Westerlund O, Kotyrlo E. Marital status and risk of dementia: A nationwide population-based prospective study from Sweden. BMJ Open. 2016;6:e008565.

10. Li X, Rastogi P, Gibbons JA, Chaudhury S. Visuo-cognitive skill deficits in Alzheimer's disease and Lewy body disease: A comparative analysis. Ann Indian Acad Neurol. 2014;17(1):12-8.

11. Podcasy JL, Epperson CN. Considering sex and gender in Alzheimer disease and other dementias. Dialogues Clin Neurosci. 2016;18(4):437-46.

12. Beam CR, Kaneshiro C, Jang JY, Reynolds CA, Pedersen NL, Gatz M. Differences between women and men in incidence rates of dementia and Alzheimer's disease. J Alzheimer's Dis. 2018;64(4):1077-83.

13. Langa KM. Cognitive aging, dementia, and the future of an aging population. In:
Future directions for the demography of aging. Washington, DC: The National Academic Press; 2018.

14. Brenowitz WD, Kukull WA, Beresford SAA, Monsell SE, Williams EC. Social relationships and risk of incident mild cognitive impairment in U.S Alzheimer's disease centers. Alzheimer Dis Assoc Disord. 2014;28(3):253-60.

15. Hamel R, Ramakers I, Oosterveld S, Melis RJ, Rikkert MO, Sistermans N, et al. 01-06-02: The influence of comorbidities on cognitive decline and conversion to dementia in patients with mild cognitive impairment. Alzheimer Dement. 2014;10(4):139.

16. Tomioka K, Kurumatani N, Hosoi H. Social participation and cognitive decline among community-dwelling older adults: A community-based longitudinal study. J Gerontol B Psychol Sci Soc Sci. 2018;73(5):799-806.

17. Sun Y, Ma W, Wu Y, Koenig HG, Wang Z. The mediating effect of depression in religiosity and cognitive function among chinese muslim elderly. Neuropsychiatry (London). 2018;08(03):1046-53. 